\title{
IMMUNOELECTRON MICROSCOPIC INVESTIGATION OF GLUTATHIONE-PEROXIDASE IN THE RAT STOMACH
}

\author{
Masanori MURAKOSHI, Rie INADA, R. Minoru SUZUKI \\ AND KEI-ICHI WATANABE*
}

\author{
Safety Research Department, Teikoku Hormone Mfg. Co. Ltd., 1604 Shimosakunobe, \\ Takatsu-ku, Kawasaki 213 and Department of Pathology*, \\ Tokai University School of Medicine, Bohseidai, \\ Isehara, Kanagawa 259-11
}

\begin{abstract}
Received for publication November 9, 1989 in revised form December 19, 1989 and re-revised form January 29, 1990
\end{abstract}

\begin{abstract}
Immunocytochemical localization of glutathione-peroxidase (GSH-PO) in the stomach was studied in rats under the following experimental conditions; 1) normal untreated 2) histamine-administration 3) atropine-administration in order to clarify the role of GSH-PO. In normal untreated group, GSH-PO was mainly observed in the central part of the gland. At higher magnification, GSH-PO was diffusely distributed in the pyramidal or oval-shaped cytoplasm. Intracellular localization of GSH-PO was predominantly observed in the cytoplasm of the parietal cells. In histamine-administered animal, GSH-PO was intensely stained in cytoplasm of the parietal cells with well-developed secretory canaliculi. In atropine-administered animal, the intensity of the GSH-PO staining in the parietal cells was remarkably decreased. By immunoelectron microscopic investigations, GSH-PO was noted in cytoplasm as small granules or lysosome-like structures.

Based on our data, it is suggested that GSH-PO in the gastric parietal cells may play an important role in the prevention of damage to the microsomes with lipid peroxides induced during the process of $\mathrm{HCl}$ secretion. We further speculated that GSH-PO within the lysosome-like structures after atropine-administration might be a result of the degradation process of the peroxidized materials.
\end{abstract}

Oxygen-derived free radicals have been implicated from pharmacological studies with mucosal lesions induced by ischemia in the stomach. Recently, Thaete et al. (19) reported that immunohistochemical localization of superoxide dismutase, an enzyme that catalyzes the dismutation of the superoxide anion as a toxic free radical, was predominantly observed in the gastric parietal cells. On the other hand, it is a well documented fact that oxygen derived free radicals result in lipid peroxidation and damage of cellular membranes with the release of intracellular components, e.g., lysosomal enzymes, leading to further tissue damage $(3,6)$. It is well known that glutathione-peroxidase (GSH-PO) is a catalyse in the reduction of lipid peroxides. Therefore, it was anticipated that the GSH-PO in the stomach may play a role in reduction of lipid peroxides.

In the present study, in order to clarify the role of GSH-PO in the stomach, at- 
tempts were made to localize the GSH-PO immunocytochemically in the stomach of normal, histamine- or atropine-administered rats.

\section{MATERIALS AND METHODS}

Animals and tissue preparation

Male Wistar rats, weighing 180 to $200 \mathrm{~g}$, were fasted overnight. Group 1 consisted of untreated controls. In group 2, rats were injected subcutaneously with 0.5 $\mathrm{mg} / \mathrm{kg}$ of histamine (Wako Pure Chemical Co.). In group 3, rats were injected subcutaneously with $0.5 \mathrm{mg} / \mathrm{kg}$ of atropine (Wako Pure Chemical Co.). In groups 2 and 3 , rats were sacrificed $2 \mathrm{hr}$ after drug administration. The rat was killed by decapitation and small pieces of the glandular stomach excised. The tissues were fixed in periodate-lysine- $4 \%$ paraformaldehyde solution (11) for 18 to $20 \mathrm{hr}$ at $4^{\circ} \mathrm{C}$ under constant agitation. The fixed tissues were then washed in $0.01 \mathrm{M}$ phosphate buffered saline (PBS), $\mathrm{pH} 7.4$, containing $20 \%$ sucrose overnight at $4^{\circ} \mathrm{C}$. Subsequently, $6 \mu \mathrm{m}$ frozen sections were prepared in a cryostat, and were mounted on albumin-coated

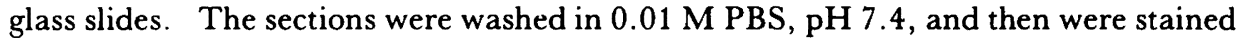
by Nakane's direct peroxidase-labeled antibody method using anti-GSH-PO IgG Fab fragment $(16,22,23)$.

For light microscopic observations of GSH-PO, $6 \mu \mathrm{m}$ frozen sections were incubated with the antibody labeled with horseradish peroxidase (HRPO, Sigma Co.) for $1 \mathrm{hr}$. After the incubation was completed, the sections were incubated in Graham-Karnovsky's reaction medium (7) which contained 3, 3'-diaminobenzidine (DAB, Wako Pure Chemical Co.) and $0.005 \% \mathrm{H}_{2} \mathrm{O}_{2}$ as the substrate for 5 to 10 min. Then the sections were counterstained for nuclei with $1 \%$ methyl green dissolved in veronal acetate buffer, $\mathrm{pH} 4.2$.

For electron microscopic observations of GSH-PO, $6 \mu \mathrm{m}$ frozen sections were incubated with HRPO labeled antibody for $6 \mathrm{hr}$. The sections were then incubated for 30 min in Graham-Karnovsky's reaction medium (7) from which the substrate, $\mathrm{H}_{2} \mathrm{O}_{2}$, was omitted, and then incubated in the fully equipped reaction medium for $5 \mathrm{~min}$.

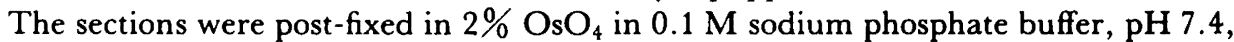
for $90 \mathrm{~min}$, dehydrated in a graded ethanol series and embedded in Quetol 812 by the inverted gelatin capsule method. Ultrathin sections were prepared with LKB ultramicrotome and were observed in a JEOL 1200EX electron microscope.

As an immunologic negative control, normal rabbit serum (NRS) IgG Fab fragment labeled with HRPO was applied on both light and electron microscopic observations instead of anti-GSH-PO IgG Fab fragment labeled with HRPO.

\section{RESULTS}

In the rat glandular stomach, GSH-PO-positive cells were localized mainly in the central part of the gland (Fig. 1A). At higher magnification, GSH-PO was distributed diffusely in the pyramidal or oval-shaped cytoplasm (Fig. 1B). The control serum (NRS) was negative for immunohistochemical localization of GSH-PO in the rat stomach (Fig. 1C). By immunoelectron microscopic observations, GSH-PO was noted in cytoplasm of the parietal cells with "tubulovesicular system" or "tubulovesicles" and secretory canaliculi (Fig.2). 
In histamine-administered rat stomach, GSH-PO-positive cells were localized in the central part of the gland (Fig. 1D). This staining pattern of GSH-PO in the glandular stomach was similar to that of the control. By immunoelectron microscopic investigations, GSH-PO was predominantly localized in the cytoplasm of the parietal cells with well-developed secretory canaliculi (Fig. 3). The intensity of the GSH-PO staining near the well-developed secretory canaliculi was stronger than that of the controls.

In atropine-administered rat stomach, GSH-PO-positive cells were localized mainly in the central part of the gland (Fig. 1E). The intensity of the GSH-PO staining was remarkably decreased. By immunoelectron microscopic investigations, GSH-PO was noted in the cytoplasm of the parietal cells with tubulovesicular system. Furthermore, GSH-PO was seen in the cytoplasm as small granules or lysosome-like structure (Figs. 4, 5).

\section{DISCUSSION}

In the gastric parietal cells it has been suggested that the tubulovesicular system is the site of production of gastric acid which is subsequently released into the secretory canaliculi $(9,18)$. In fact, gastric acid secretion is accompanied by ultrastructural alterations in the parietal cells. Many researchers agree that the ultrastructural responses to stimulants such as histamine, gastrin or insulin include a proliferation of secretrory canaliculi and a depletion of tubulovesicular system $(1,5,18,20)$. Thus, gastric acid-secreting and non-secreting prietal cells can be easily classified in the gastric gland by ultrastructural investigations.

In the present study, we found that immunohistochemical localization of GSH$P O$ in the rat stomach was detected in the parietal cells. The gastric parietal cell maintains a steep ionic gradient as it secretes $\mathrm{HCl}$ and must tolerate a high hydrogen ion concentration and ionic gradients are highly vulnerable to intracellular superoxide anion concentrations (2). Recently, Thaete et al. (19) reported that superoxide dismutase, an enzyme that catalyzes the dismutation of superoxide anion as a toxic free radical, was predominantly localized in the gastric parietal cells of the rats by immunohistochemical investigations. In addition, production of free radicals may initiate very rapid lipid peroxidation. It is generally accepted that lipid peroxidation is the reaction of oxidative deterioration of lipids and peroxidation involves the direct action of oxygen and lipid to form free radical intermediates and to produce semistable

FIG. 1A. Immunohistochemical localization of GSH-PO in control rat glandular stomach. GSH$\mathrm{PO}$ is observed mainly in the central part of the gland. Peroxidase-labeled antibody method. $\times 100$

FIG. 1B. Higher magnification of Fig. 1A. GSH-PO is diffusely distributed in the pyramidal or oval shaped cytoplasm. Peroxidase-labeled antibody method. $\times 160$

FIG. 1C. Using control serum (Normal rabbit serum), no immunohistochemical reaction is seen in rat glandular stomach. Peroxidase-labeled antibody method. $\times 100$

FIG. 1D. Immunohistochemical localization of GSH-PO in histamine-administered rat glandular stomach. Peroxidase-labeled antibody method. $\times 100$

FIG. 1E. Immunohistochemical localization of GSH-PO in atropine-administered rat glandular stomach. The intensity of the GSH-PO staining is remarkably decreased. Peroxidase-labeled antibody mothod. $\times 100$ 


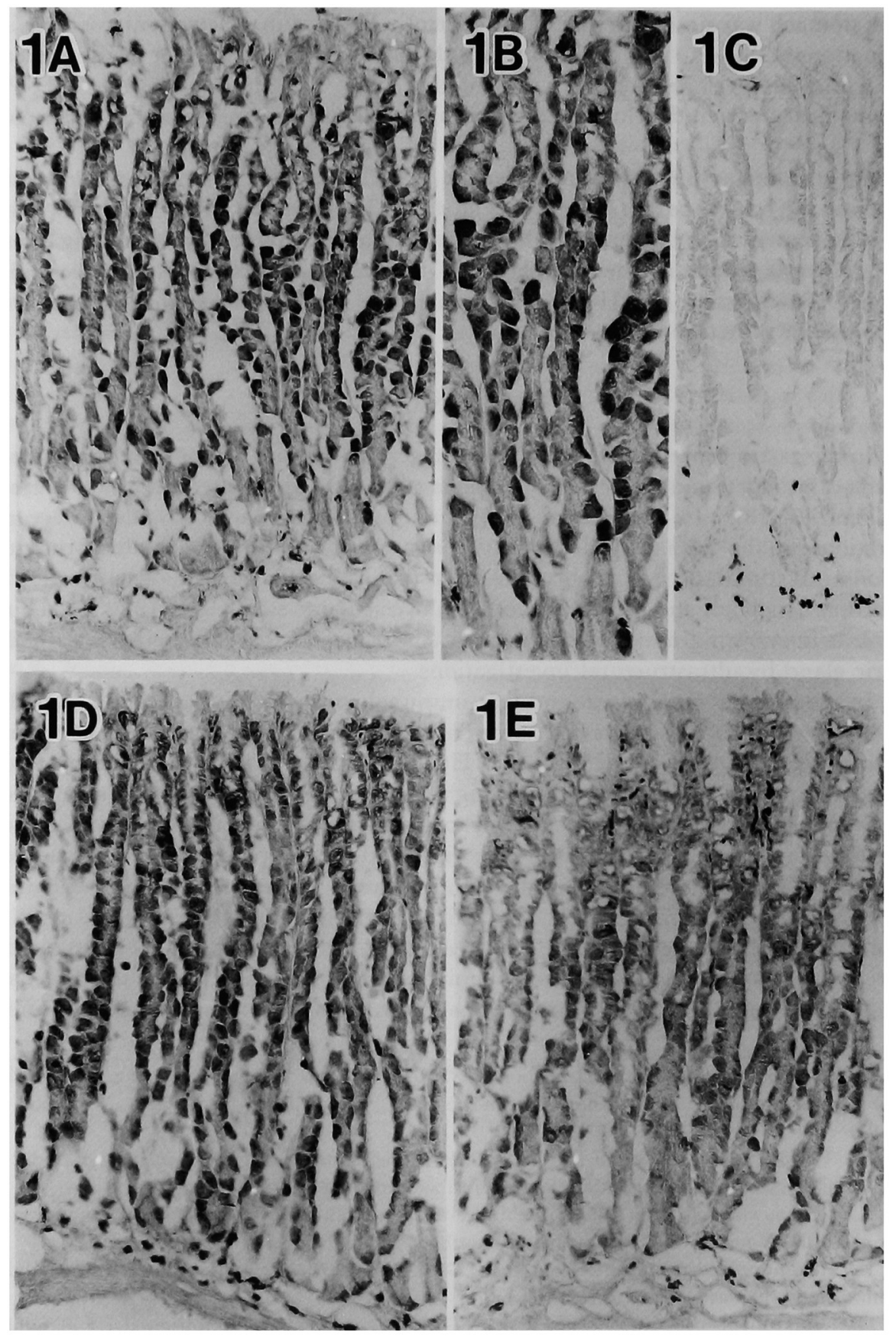



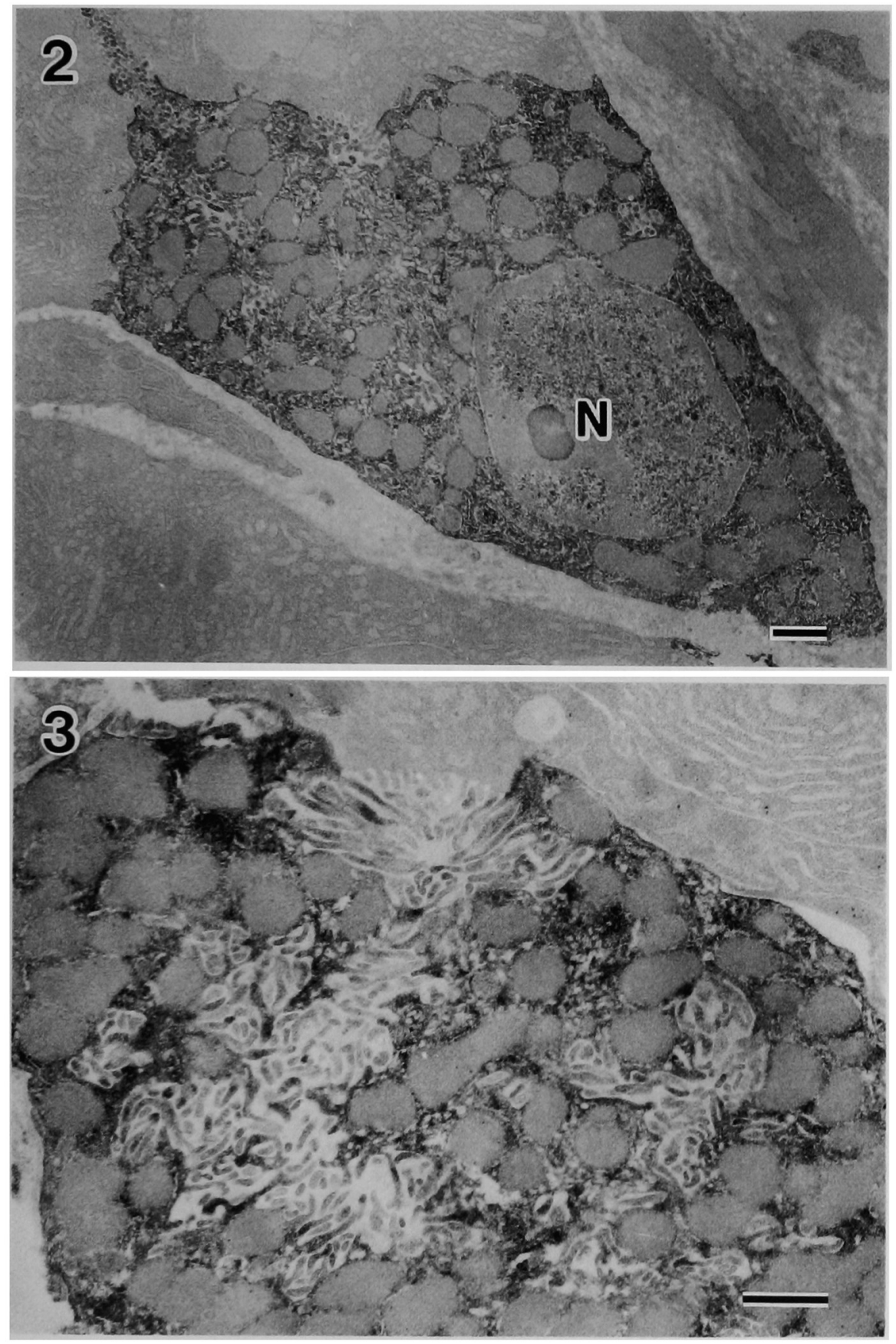

Fic. 2. Immunocytochemical localization of GSH-PO in the parietal cells of control rat stomach. GSH-PO is seen in cytoplasm. N: Nucleus. $\mathrm{Bar}=1 \mu \mathrm{m} \times 7,000$

FIG. 3. Immunocytochemical localization of GSH-PO in the parietal cells of histamine-administered rat stomach. Secretory canaliculi is well developed. GSH-PO is clearly detected in cytoplasm. $\mathrm{Bar}=1 \mu \mathrm{m} \times 12,000$ 

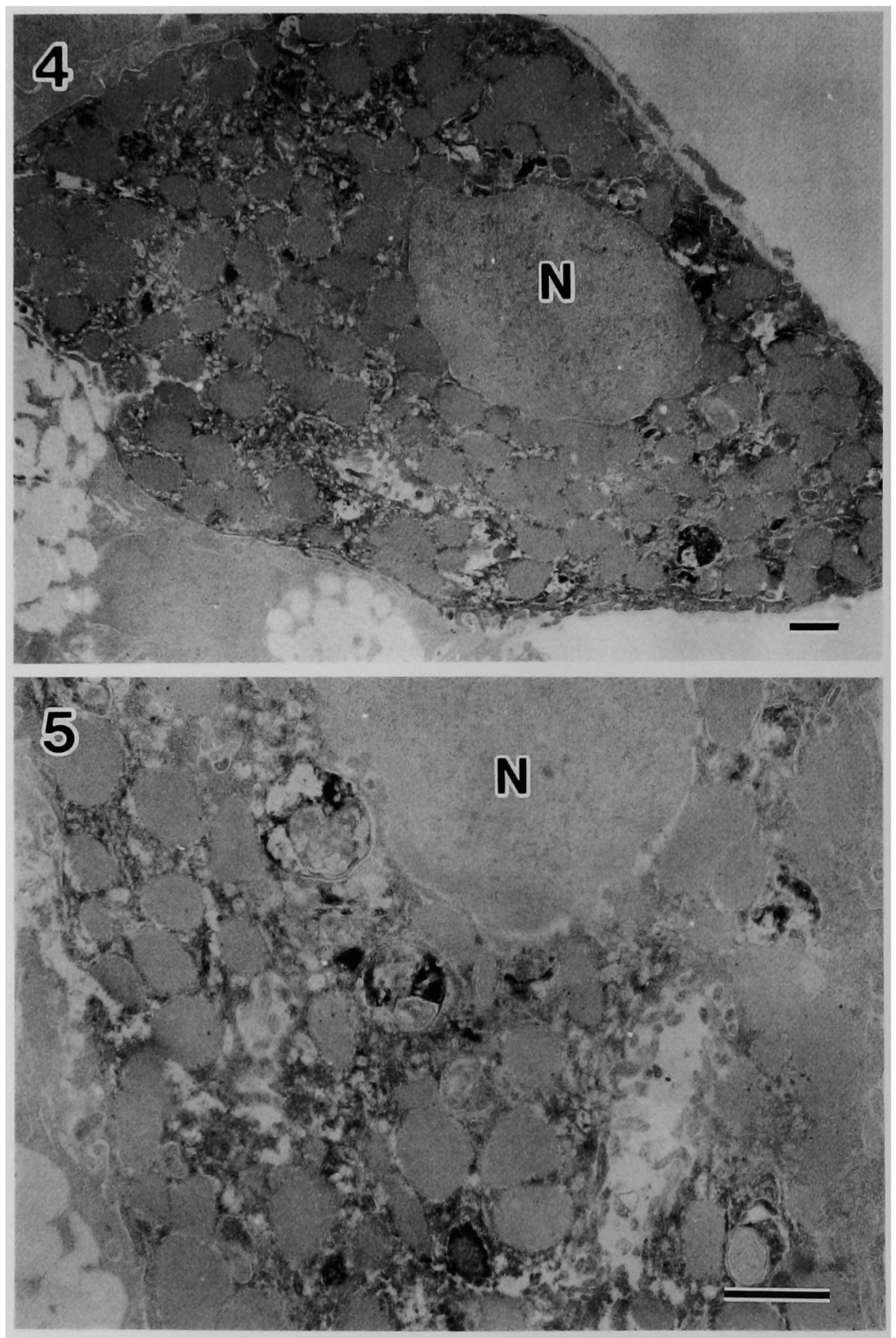

Figs. 4, 5. Immunocytochemical localization of GSH-PO in the parietal cells of atropine-administered rat stomach. GSH-PO is seen as small granules or lysosome-like structures. N: Nucleus. Bars $=1 \mu \mathrm{m}$ Fig. $4 \times 7,000$ Fig. $5 \times 15,000$ 
peroxides. Thus, free radicals result in the lipid peroxidation and damage of cellular membrane with release of intracellular components, e.g., lysosomal enzymes, leading to further tissue damage $(3,6)$. GSH-PO has been well recognized that it effectively reduces the lipid peroxides.

Therefore, GSH-PO in the gastric parietal cells might play an important role in prevention of damage with lipid peroxides induced during the process of $\mathrm{HCl}$ production and/or secretion.

By immunoelectron microscopic investigations, GSH-PO was predominantly localized in the cytoplasm of the gastric parietal cells. It is generally accepted that tubulovesicular system and secretory canaliculi is part of a system of membranes which moves rapidly between cytoplasm and surface on appropriate stimulation (4, 10). Thus, gastric parietal cells are rapidly transformed between acid-secreting and non-secreting on appropriate stimulation. In this respect, lipid peroxidation may occur in the microsomes including tubulovesicular system and secretory canaliculi. In fact, the microsomal membranes contain a relatively large amount of polyunsaturated fatty acid in their phospholipid and the microsomes are very liable to lipid peroxidation and concurrent damage $(17,21)$. Therefore, GSH-PO in the gastric parietal cells might play an important role in prevention of damage to the microsomes with lipid peroxidation. By histamine-administration, immunoelectron microscopically, GSH-PO was predominantly localized in the cytoplasm and the intensity of GSH-PO staining near the well-developed secretory canaliculi was stronger than that of the control. In contrast, by atropine-administration, the intensity of the GSH-PO staining was remarkably decreased. The findings may indicate that the lipid peroxidation rate is less in the non-secreting parietal cells after atropine-administration than in the acidsecreting parietal cells.

Based on our data and these facts, it is suggested that GSH-PO in the gastric parietal cells might play an important role in prevention of damage to membrane with lipid peroxides induced during the process of $\mathrm{HCl}$ secretion.

On the other hand, immunoelectron microscopic localization of GSH-PO in the parietal cells after atropine-administration was observed in the form of characteristic lysosome-like structures. Similar findings have been observed in the rat testicular-or peritoneal-macrophages and the glandular epithelial cells of the prostate by us (1215). In this case, we postulated that lipid peroxidation may be continued even during the process of the degradation within the lysosome-like structure. Thus, GSH-POpositive granules are thought to be a result of the degradation process of the peroxidized materials. Therefore, the results of the present study suggest that degradation of the microsomes in the parietal cells after atropine-administration may be increased. The true nature of GSH-PO in the gastric parietal cells after atropine-administration is to be further clarified.

\section{REFERENCES}

1. Adkins, R. B., Ende, N. and Goggel, W. C.: A correlation of parietal cells activity with ultrastructural alterations. Surgery 62; 1059-1069, 1967.

2. Durbin, R. P., Michelangeli, F. and Nickel, A.: Acute transport and ATP in frog gastric mucosa. Biochim. Biophys. Acta 367; 177-189, 1974. 
3. Fong, K. L., MaCay, P. B., Payer, J. L., Keele, B. B. and Misra, H.: Evidence that peroxidation of lysosomal membranes is initiated by hydoxy free radicals produced during flavin enzyme activity. J. Biol. Chem. 248; 7792-7797, 1973.

4. Forte, T. M., Machen, T. E., and Forte, J. G.: Ultrastructural changes in oxyntic cells associated with secretory function. A membrane-recycling hypothesis. Gastroenterology 73; 941-955, 1977.

5. Frexions, J., Carballido, M. and Louis A.: Effect of pentagastrin stimulation on human parietal cells. Am. J. Dig. 16; 1065-1074, 1971.

6. Fridovich, I.: The biology of oxygen radicals. The superoxide radical is an agent of oxygen toxicity. Superoxide dismutase provide an important defense. Science 201; 875-880, 1978.

7. Graham, R. C. and Karnovsky, M. J.: The early stages of absorption of injected horseradish peroxidase in the proximal tubules of mouse kidney. J. Histochem. Cytochem. 14; 291-302, 1966.

8. Hubner, G., Klein, H. J., and Eder, H.: Feinstrukturelle Untersuchungen and der Fundusschleimhaud des Rattemagens nach Stimuleirung mit pentogastrin und Betazol. Verhandl. Deutch. Ges. für Pathol. 53; 247-253, 1969.

9. Itho, S.: The endoplasmic reticulum of gastric parietal cells. J. Biophys. Biochem. Cytol. 11; 333-347, 1961.

10. Ito, S. and Schofield, G. C.: Studies on the depletion and accumulation of microvilli and changes in the tubulovesicular compartment of mouse parietal cells in relation to gastric acid secretion. J. Cell Biol. 63; 364-382, 1974.

11. McLean, I. W. and Nakane, P. K.: Periodate-lysine-paraformaldehyde fixative. A new fixative for immunoelectron microscopy. J. Histochem. Cytochem. 22; 1077-1083, 1974.

12. Murakoshi, M., Osamura, Y., Yoshimura, S. and Watanabe, K.: Characteristic immunocytochemical localization of glutathione-peroxidase in rat testicular interstitial macrophages. Acto histochem. cytochem. 16;588-595, 1983.

13. Murakoshi, M., Osamura, Y., Yoshimura, S. and Watanabe, K.: Immunohisto-cytochemical localization of glutathione-peroxidase in the rat testis. Acta hitochem. cytochem. 16; 335-345, 1983.

14. Murakoshi, M., Ikeda, K. and Watanabe, K.: Immunocytochemical localization of glutathione-peroxidase in rat peritoneal macrophages. Acta hitochem. cytochem. 19; 125-133, 1986.

15. Murakoshi, M., and Watanabe, K.: Alteration of glutathione-peroxidase in rat ventral prostate. Acta hitochem. cytochem. 21; 283-289, 1988.

16. Nakane, P. K.: Recent progress in the peroxidase-labeled antibody method. Ann N.Y. Acad. Sci. 234; 203-211, 1975.

17. Robinson, J. D.: Structural changes in microsomal suspensions. Arch. Biochem. Biophys. 112; 170-179, 1965.

18. Sedar, A.W. and Friendman, M. H. F.: Correlation of the fine structure of the gastric parietal cell with functional activity. J. Biophys. Biochem. Cytol. 11;349-363, 1961.

19. Theate, L. G., Crough, R. K. and Spicer, S. S.: Immunolocalization of copper-zinc superoxide dismutase. II Rat. J. Histochem. Cytochem. 33; 803-808, 1985.

20. Vial, J. D. and Orrego, H.: Electron microscopic observations of the fine structure of parietal cells. J. Biophys. Biochem. Cytol. 7; 367-372, 1960.

21. Victoria, E. J. and Barkaer, A. A.: Peroxidation of microsomal membrane protein-lipid complexes. Lipids 4; 582-588, 1969.

22. Watanabe, K.: Lipid peroxidation and cell injury. Tr. Soc. Pathol. Jpn. 76; 39-74, 1986 (In Japanese).

23. Yoshimura, S., Izumi, S., Komatsu, N., Murakoshi, M., Osamura, Y. and Watanabe, K.: Biochemical and immunocytochemical studies on GSH-Peroxidase in various organs of rats. Cell Struct. Funct. 3; 409, 1978. 